\title{
Shared Decision Making in Prosthodontics and Implant Dentistry
}

\author{
Pravinkumar G Patil
}

International Journal of Prosthodontics and Restorative Dentistry (2021): 10.5005/jp-journals-10019-1307

Traditionally, the patient-clinician relationship was authoritarian, in which the clinician made the decisions on behalf of the patient. ${ }^{1}$ In recent years, there has been a paradigm shift in such relationships and patient-centered care has been taking up a new concept in clinical medicine. ${ }^{1}$ The patients are expecting their active involvement in the decision of their own health. Hence, the concept of shared decision making (SDM) is slowly becoming a common practice. Shared decision making is a process in which clinicians and patients work together sharing information about options to reach mutual agreement on the best course of action. ${ }^{1,2}$ Convincing evidence has shown that the use of the SDM improves treatment outcomes and increases patient and clinician satisfaction in healthcare fields. ${ }^{2,3}$

Though the concept of SDM is an emerging trend in clinical medicine, there is a lack of information in the dental literature. ${ }^{4}$ Benecke et al. ${ }^{5}$ studied of patients' autonomy preferences in dentistry in comparison to other medical domains with 100 dental patients attending 16 dentists in a university-based prosthodontic clinic. The results revealed that the decisions about prosthodontic management were relevant for an SDM by both clinicians and patients. More patient autonomy was desired for treatment decisions in prosthodontic care compared with general medical practice. ${ }^{5}$ Few dental practitioners are using patient decisionmaking aids (PDAs) to help them choose among reasonable alternative treatment options. ${ }^{4}$ Asa'ad $^{6}$ reviewed the literature available on the roles of informed consent and PDAs as a part of the SDM process and concluded that both play an important role. There is a need for further development of the PDAs to ensure a satisfactory integration of patient involvement in SDM. ${ }^{6}$

Compared with all other dental disciplines, implant dentistry has evolved with innovations and progressive developments in recent years. Improved diagnostic procedures, novel surgical and restorative techniques, and CAD-CAM technology constantly reaching new heights to make the treatment more and more predictable. There has been an explosion in the use of implant therapies in dentistry, but very little is known about the decisionmaking processes involved. Alzahrani and Gibson ${ }^{3}$ have done a scoping review of 21 relevant studies on the role of SDM in dental implant consultations. They observed that no studies to date have examined how patients and dentists engage interact during
Department of Prosthodontics, Division of Restorative Dentistry, School of Dentistry, International Medical University, Kuala Lumpur, Malaysia

Corresponding Author: Pravinkumar G Patil, Department of Prosthodontics, Division of Restorative Dentistry, School of Dentistry, International Medical University, Kuala Lumpur, Malaysia, Phone: +601135022042, e-mail: pravinandsmita@yahoo.co.in

How to cite this article: Patil PG. Shared Decision Making in Prosthodontics and Implant Dentistry. Int J Prosthodont Restor Dent 2021;11(1):2.

Source of support: Nil

Conflict of interest: None

implant consultations and in decisions to place dental implants. Treatment planning with dental implants is a big decision. The implant procedures are a balancing act among a wide range of procedures, technologies, clinician expertise, patient expectations, maintenance, complications, and management strategies. There is a need to explore newer strategies to practice SDM in Prosthodontics and Implant Dentistry to ensure enhanced clinicians' and patients' satisfaction.

\section{References}

1. Ryan $F$, Cunningham S. Shared decision making in healthcare. Faculty Dent J 2014;5(3):124027. DOI: 10.1308/204268514X14017784505970.

2. Coulter A, Collins A. Making shared decision-making a reality. London: King's Fund; 2011.

3. Alzahrani AAH, Gibson BJ. Scoping review of the role of shared decision making in dental implant consultations. JDR Clin Trans Res 2018;3(2):130-140. DOI: 10.1177/2380084418761340.

4. Johnson BR, Schwartz A, Goldberg J, et al. A chairside aid for shared decision making in dentistry: a randomized controlled trial.J Dent Educ 2006;70(2):133-141. DOI: 10.1002/j.0022-0337.2006.70.2.tb04069.x.

5. Benecke M, Kasper J, Heesen C, et al. Patient autonomy in dentistry: demonstrating the role for shared decision making. BMC Med Inform Decis Mak 2020;20(1):318. DOI: 10.1186/s12911-020-01317-5.

6. Asa'ad F. Shared decision-making (SDM) in dentistry: a concise narrative review. J Eval Clin Pract 2019;25(6):1088-1093. DOI: 10.1111/ jep.13129.

\footnotetext{
(c) Jaypee Brothers Medical Publishers. 2021 Open Access This article is distributed under the terms of the Creative Commons Attribution 4.0 International License (https://creativecommons.org/licenses/by-nc/4.0/), which permits unrestricted use, distribution, and non-commercial reproduction in any medium, provided you give appropriate credit to the original author(s) and the source, provide a link to the Creative Commons license, and indicate if changes were made. The Creative Commons Public Domain Dedication waiver (http://creativecommons.org/publicdomain/zero/1.0/) applies to the data made available in this article, unless otherwise stated.
} 